\title{
Obesity prevalence in Mexico: impact on health and economic burden
}

\author{
Ketevan Rtveladze ${ }^{1, *}$, Tim Marsh ${ }^{1}$, Simon Barquera ${ }^{2}$, Luz Maria Sanchez Romero², \\ David Levy ${ }^{3}$, Guillermo Melendez ${ }^{4}$, Laura Webber ${ }^{1}$, Fanny Kilpi ${ }^{1}$, Klim McPherson ${ }^{5}$ and \\ Martin Brown ${ }^{1}$ \\ 'Micro Health Simulations, Victoria House 7th Floor, Southampton Row, London WC1B 4AD, UK: \\ ${ }^{2}$ Instituto Nacional de Salud Pública, Cuernavaca, Morelos, México: ${ }^{3}$ Georgetown University, Washington, \\ DC, USA: ${ }^{4}$ Fundación Mexicana para la Salud, Tlalpan, México DF: ${ }^{5}$ New College, Oxford, UK
}

Submitted 3 July 2012: Final revision received 5 December 2012: Accepted 2 January 2013: First published online 1 February 2013

\begin{abstract}
Objective: Along with other countries having high and low-to-middle income, Mexico has experienced a substantial change in obesity rates. This rapid growth in obesity prevalence has led to high rates of obesity-related diseases and associated health-care costs.

Design: Micro-simulation is used to project future BMI trends. Additionally thirteen BMI-related diseases and health-care costs are estimated. The results are simulated for three hypothetical scenarios: no BMI reduction and BMI reductions of $1 \%$ and $5 \%$ across the population.

Setting: Mexican Health and Nutrition Surveys 1999 and 2000, and Mexican National Health and Nutrition Survey 2006.

Subjects: Mexican adults.

Results: In 2010, $32 \%$ of men and $26 \%$ of women were normal weight. By 2050 , the proportion of normal weight will decrease to $12 \%$ and $9 \%$ for males and females respectively, and more people will be obese than overweight. It is projected that by 2050 there will be 12 million cumulative incidence cases of diabetes and 8 million cumulative incidence cases of heart disease alone. For the thirteen diseases considered, costs of \$US 806 million are estimated for 2010, projected to increase to \$US 1.2 billion and \$US 1.7 billion in 2030 and 2050 respectively. A $1 \%$ reduction in BMI prevalence could save \$US 43 million in health-care costs in 2030 and \$US 85 million in 2050.

Conclusions: Obesity rates are leading to a large health and economic burden. The projected numbers are high and Mexico should implement strong action to tackle obesity. Results presented here will be very helpful in planning and implementing policy interventions.
\end{abstract}

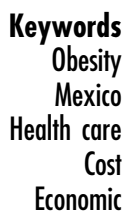

Mexico has experienced a rapid increase in wealth in recent decades, bringing a significant shift in socio-economic status and a geographical shift from rural to urban among its population. This has led to changes in diet that are detrimental to health: an increase in sedentary behaviour and increased access to low-priced highly energy-dense foods. As a result, rapid growth in the prevalence of obesity and obesity-related non-communicable diseases (NCD) has been observed with a lack of prevention programmes to curb this rise. A significant increase in obesity was reported between 2000 and $2006^{(1)}$ and is expected to impose a substantial burden in terms of disease outcomes and health-care costs. Nutrition-related chronic diseases such as type 2 diabetes and hypertension are associated with increased obesity rates ${ }^{(2)}$. CVD and type 2 diabetes are now considered the main causes of adult mortality in Mexico ${ }^{(1)}$.
According to the Ministry of Health, the number one leading cause of mortality in 2008 was diabetes (14\%), followed by IHD (11\%) and stroke (5.6\%). When the mortality prevalence of the different types of cancers was combined, it became the third most common cause of mortality ${ }^{(3)}$.

In 2004, NCD caused $75 \%$ of the total deaths and $68 \%$ of total disability-adjusted life years in $\mathrm{Mexico}^{(4)}$. Overweight and obesity are the main risk factor for a larger burden of NCD. According to a report by the Organisation for Economic Co-operation and Development, for every extra $15 \mathrm{~kg}$, the probability of early death increases by $30 \%{ }^{(5)}$. In 2008 , the loss of productivity due to early death that is attributable to overweight and obesity in Mexico was \$US 1931 million. The total direct cost estimated for the treatment of these co-morbidities 
(CVD, stroke, hypertension, cancer and diabetes mellitus) reached a total of $\$$ US $3 \cdot 2$ million, representing $33 \cdot 2 \%$ of the total health-care expenditure in 2008. This is an increase of $61 \%$ from the cost in $2000^{(6)}$.

In the present paper, we map the trajectory of future obesity trends in Mexico to 2050 based a method that utilizes the best data currently available and that is already applied in the UK and the USA ${ }^{(7)}$. We measure the consequences of these trends on future incidence of disease and health-care costs. In addition, we estimate the impact of reducing obesity rates by $1 \%$ and $5 \%$ on the incidence of and mortality rates from obesity-related diseases. The estimates are of interest not only in Mexico, as one of the low- and middle-income nations with higher rates of obesity, but also are of interest to other low- and middleincome nations, especially in Latin America.

\section{Design}

\section{BMI data}

The BMI data $\left(\mathrm{kg} / \mathrm{m}^{2}\right)$ were obtained from the 2000 Mexican Health and Nutrition Survey (Encuesta Nacional en Salud (ESNA) $)^{(8)}$ and the 2006 Mexican National Health and Nutrition Survey (Encuesta Nacional de Salud y Nutrición (ENSANUT) $)^{(9)}$. In addition, data from 1993 for males and females ${ }^{(10)}$ and from 1999 for females aged 20-49 only (Encuesta Nacional de Nutrición (ENN) 1999) ${ }^{(11)}$ were utilized to project obesity trends. Adult BMI distributions were distinguished by age and gender in three BMI categories: normal weight $\left(\leq 24.9 \mathrm{~kg} / \mathrm{m}^{2}\right)$, overweight $\left(25 \cdot 0-29 \cdot 9 \mathrm{~kg} / \mathrm{m}^{2}\right)$ and obese $\left(\geq 30 \cdot 0 \mathrm{~kg} / \mathrm{m}^{2}\right)$.

\section{Disease data}

A review of the epidemiological and academic literature was undertaken to determine the country-specific incidence, survival or case fatality rates and annual medical costs for the following, by age and sex: (i) type 2 diabetes, CHD (or IHD, myocardial infarction), stroke and knee osteoarthritis as obesity-related diseases; and (ii) cancer of the breast, kidney, colon/rectum, oesophagus, endometrium and gallbladder as obesity-related cancers. Relative risks (RR) by BMI for each disease were obtained from a systemic review of the epidemiological literature ${ }^{(12)}$. These RR were applied to the Mexican population, assuming that the risks do not differ from those in European populations. The population free of disease was assigned a probability of getting a specific disease defined by the RR at the beginning of a particular year. As a consequence, they might recover or be ill and die from the specified disease or from an unspecified cause. The development of disease is defined by survival statistics and life expectancy.

Some of the disease data, such as incidence and prevalence, were provided to us by our collaborators (diabetes, stroke, IHD and hypertension), but much of the requisite data could not be obtained during the duration of the study. Survival for CHD was not available; therefore we used myocardial infarction survival, calculated from case fatality figures and applied it to 1-year CHD survival, assuming that myocardial infarction and CHD have the same survival rate. Mortality both for CHD and stroke is from the WHO mortality and burden of disease estimates ${ }^{(13)}$.

Cancer incidence and mortality data were obtained from the GLOBOCAN Project $2008^{(14)}$; survival data were available only for two of them, breast and colorectal. For others, figures from the USA have been used ${ }^{(7)}$. We applied the US survival figures to Mexico, assuming they are the same within these two countries. No data on the incidence of knee osteoarthritis were available and so US data were used as a proxy to calculate Mexican figures. The disease rates reflect the obesity distribution of the originating country (the USA in this case). When using these data for another country, we removed the effect of the BMI distribution, taking the rates of the healthy individuals, and then used the obesity rates of the receiving country to calculate an estimate of the rates in Mexico.

The Mexican Institute of Social Security (Instituto Mexicano del Seguro Social) provides detailed disease cost data. The costs are presented as unit costs, i.e. the cost of each patient during hospital admission ${ }^{(15)}$. However, the micro-simulation program only incorporates total costs for health care and per unit costs cannot be entered into the program at this stage. The evaluation methods of other published articles were different. In order to be consistent with the data estimations and to make costs more reliable, the US health-care costs were chosen and applied to Mexico by adjusting the disease ratios. Thus, the diabetes cost ${ }^{(16)}$ was taken as the constant and most reliable number from Mexico. The ratio (e.g. how many times higher one disease cost is than the other) of US health-care costs was applied to each disease. For example, the cost of diabetes in Mexico is $\approx$ \$US 2 billion; the costs of all diseases in the USA are known. To calculate the unknown cost for CHD in Mexico we take the cost of CHD in the USA ( $\approx$ \$US 132 billion) divided by the US diabetes cost ( $\$$ US 132 billion/\$US 109 billion $=1 \cdot 211$ ), then multiply this ratio with the Mexican diabetes cost $(1 \cdot 211 \times$ \$US 2 billion). The rough estimate of the CHD costs in Mexico is therefore \$US $2 \cdot 4$ billion. All costs are for 2000 and are not inflated to the latest year or discounted. Costs are presented in \$US.

\section{Simulation model}

We employed the two-stage modelling process developed by the UK Foresight working group ${ }^{(17-19)}$. In the first module, we fit multivariate, categorical regression models to the cross-sectional BMI data series. We included sex, age and calendar year as covariates and constrained the predicted proportions of the population for each BMI category. The cross-sectional data were used to construct longitudinal trajectories to 2050 by creating pseudo cohorts 
within the population. Size and age distributions were based on published projections from the UN population database ${ }^{(20)}$. We simulated 5 million individuals by sex and age, and scaled up the simulated population to reflect the total population of Mexico. The 95\% confidence interval for the projected prevalence was calculated from the Bayesian posterior distribution of the regression parameters. Further details of the two-part modelling process can be found elsewhere ${ }^{(19)}$.

For the present analyses, we reduced the BMI by a constant percentage across the whole population ( $1 \%$ and $5 \%$ in this case) to test the potential of the amended BMI prevalence. This is to say that everyone's BMI was reduced by $1 \%$ or $5 \%$ only in 2010 , and it is then assumed that the trend will continue from the decreased level. Each simulation consisted of 5 million Monte Carlo ${ }^{(21)}$ trials.

\section{Results}

Obesity is projected to increase across all age groups. Particularly high levels are seen in middle-aged men (50-59 years) and older females ( $\geq 60$ years), as shown in Table 1 . As shown in Table 2, obesity rates are expected to increase for both males and females. In 2010, 68\% (41\% overweight and $27 \%$ obese) of the male population is estimated to be overweight or obese $\left(\mathrm{BMI} \geq 25 \cdot 0 \mathrm{~kg} / \mathrm{m}^{2}\right)$. The rate is expected to increase to $88 \%$ (34\% overweight and $54 \%$ obese) by 2050 . An increase is also projected among females, with rates estimated at 74\% (37\% overweight and $37 \%$ obese) in 2010 increasing to about $91 \%$ by 2050 (34\% overweight and $57 \%$ obese).

Using the projected BMI distribution, we simulated the data of thirteen BMI-related diseases. Table 3 shows the cumulative incidence cases in the total population for males and females projected to 2050. It is clear that the disease burden is increasing every year, resulting in a doubling of prevalence rates by 2050. Obesity-related CHD and stroke and the cancers are projected to more than double between 2010 and 2050. For the other obesity-related diseases, between 2010 and 2050, the rates will nearly double for hypertension and knee osteoarthritis; the highest prevalence rate will be seen for diabetes which more than doubles.

Table 4 shows the effect of a $1 \%$ (Scenario 1 ) and a $5 \%$ (Scenario 2) reduction in the rate of overweight and obesity (from a mean BMI of 28.5 to $28 \cdot 2 \mathrm{~kg} / \mathrm{m}^{2}$ (-1\%) and to $\left.27 \cdot 1 \mathrm{~kg} / \mathrm{m}^{2}(-5 \%)\right)$ that starts in 2010 on cancers, CHD and stroke, knee osteoarthritis, type 2 diabetes and hypertension. A reduction in BMI of $1 \%$ across the population will result in 13051 fewer cumulative cancer cases in 2030 compared with an unchanged 2010 trend and 28277 fewer cases in 2050. The CHD and stroke cases are reduced by 118183 cumulative cases in 2030 and by 400227 cases in 2050. Diabetes cases are reduced by

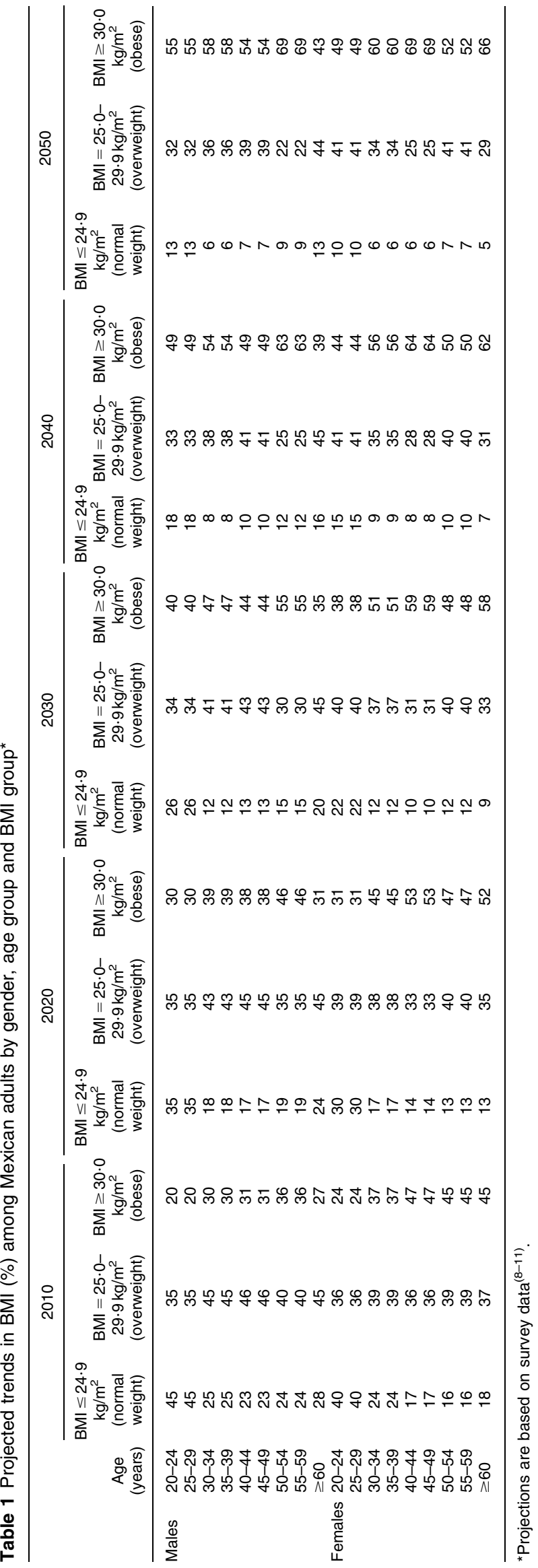


Table 2 Projected trends in BMI (\%) for adult Mexican males and females by BMI group*

\begin{tabular}{lcccc}
\hline & Year & $\begin{array}{c}\text { BMI } \leq 24 \cdot 9 \mathrm{~kg} / \mathrm{m}^{2} \\
\text { (normal weight) }\end{array}$ & $\begin{array}{c}\mathrm{BMI}=25 \cdot 0-29 \cdot 9 \mathrm{~kg} / \mathrm{m}^{2} \\
\text { (overweight) }\end{array}$ & $\begin{array}{c}\mathrm{BMI} \geq 30 \cdot 0 \mathrm{~kg} / \mathrm{m}^{2} \\
\text { (obese) }\end{array}$ \\
\hline Males & 2010 & 32 & 41 & 27 \\
& 2020 & 25 & 40 & 35 \\
& 2030 & 19 & 38 & 43 \\
Females & 2040 & 15 & 36 & 49 \\
& 2050 & 12 & 34 & 54 \\
& 2010 & 26 & 37 & 37 \\
& 2020 & 21 & 36 & 43 \\
& 2030 & 15 & 36 & 49 \\
\end{tabular}

${ }^{*}$ Projections are based on survey data ${ }^{(8-11)}$.

Table 3 Cumulative incidence cases of various obesity-related diseases from year 2010 to 2050 (per 100000 of the population in 2010) among Mexican adults according to different scenarios

\begin{tabular}{|c|c|c|c|c|c|c|c|c|c|c|c|}
\hline & \multirow[b]{2}{*}{ Year } & \multicolumn{2}{|c|}{ Eight cancers } & \multicolumn{2}{|c|}{$\mathrm{CHD}$ and stroke } & \multicolumn{2}{|c|}{ Knee osteoarthritis } & \multicolumn{2}{|c|}{ Type 2 diabetes } & \multicolumn{2}{|c|}{ Hypertension } \\
\hline & & $n$ & $95 \% \mathrm{Cl}$ & $n$ & $95 \% \mathrm{Cl}$ & $n$ & $95 \% \mathrm{Cl}$ & $n$ & $95 \% \mathrm{Cl}$ & $n$ & $95 \% \mathrm{Cl}$ \\
\hline \multirow[t]{5}{*}{ Scenario 0} & 2010 & 41 & 39,43 & 217 & 213, 221 & 623 & 616,630 & 296 & 301, 291 & 413 & 407, 419 \\
\hline & 2020 & 481 & 475,487 & 2456 & 2443, 2469 & 6988 & 6966,7010 & 3540 & 3524,3556 & 4819 & 4801,4837 \\
\hline & 2030 & 991 & 983, 999 & 5074 & 5056,5092 & 13590 & 13560,13620 & 7350 & 7328, 7372 & 9786 & 9761,9811 \\
\hline & 2040 & 1576 & 1566,11586 & 8305 & 8282,8328 & 20541 & 20505,20577 & 11681 & 11654,11708 & 15339 & 15308,15370 \\
\hline & 2050 & 2264 & 2252,2276 & 12203 & 12176,12230 & 27925 & 27884,27966 & 16558 & 16526,16590 & 21523 & 21487,21559 \\
\hline \multirow[t]{5}{*}{ Scenario 1} & 2010 & 40 & 39,42 & 212 & 208,216 & 601 & 594,608 & 274 & 269,279 & 397 & 391,403 \\
\hline & 2020 & 476 & 470,482 & 2384 & 2371, 2397 & 6800 & 6778,6822 & 3292 & 3277,3307 & 4642 & 4624,4660 \\
\hline & 2030 & 973 & 965,981 & 4911 & 4893,4929 & 13264 & 13235,13293 & 6804 & 6783,6825 & 9428 & 9403,9453 \\
\hline & 2040 & 1546 & 1536,1556 & 7984 & 7962, 8006 & 20068 & 20033,20103 & 10819 & 10793,10845 & 14783 & 14753,14813 \\
\hline & 2050 & 2225 & 2213,2238 & 11651 & 11625,11677 & 27304 & 27263,27345 & 15348 & 15318,15378 & 20770 & 20735,20805 \\
\hline \multirow[t]{5}{*}{ Scenario 2} & 2010 & 39 & 37,41 & 193 & 189, 197 & 569 & 562,576 & 214 & 210,218 & 354 & 349,359 \\
\hline & 2020 & 456 & 450,462 & 2173 & 2161,2185 & 6399 & 6378,6420 & 2690 & 2676,2704 & 4235 & 4218,4252 \\
\hline & 2030 & 934 & 926,942 & 4452 & 4435,4469 & 12582 & 12553,12611 & 5739 & 5720,5758 & 8695 & 8671,8719 \\
\hline & 2040 & 1501 & 1491,1511 & 7245 & 7224,7266 & 19009 & 18975,19043 & 9245 & 9421,9269 & 13712 & 13683,13741 \\
\hline & 2050 & 2150 & 2139,2161 & 10602 & 10577,10627 & 25850 & 25811,25889 & 13135 & 13107,13163 & 19303 & 19269,19337 \\
\hline
\end{tabular}

Scenario 0, no BMI reduction; Scenario 1, $1 \%$ reduction in BMI across the population; Scenario $2,5 \%$ reduction in BMI across the population.

Table 4 Cumulative incidence cases of various obesity-related diseases avoided from year 2010 to 2050 (per 100000 of the population in 2010) among Mexican adults according to different scenarios

\begin{tabular}{|c|c|c|c|c|c|c|c|c|c|c|c|}
\hline & \multirow[b]{2}{*}{ Year } & \multicolumn{2}{|c|}{ Eight cancers } & \multicolumn{2}{|c|}{$\mathrm{CHD}$ and stroke } & \multicolumn{2}{|c|}{ Knee osteoarthritis } & \multicolumn{2}{|c|}{ Type 2 diabetes } & \multicolumn{2}{|c|}{ Hypertension } \\
\hline & & $n$ & $95 \% \mathrm{Cl}$ & $n$ & $95 \% \mathrm{Cl}$ & $n$ & $95 \% \mathrm{Cl}$ & $n$ & $95 \% \mathrm{Cl}$ & $n$ & $95 \% \mathrm{Cl}$ \\
\hline \multirow[t]{5}{*}{ Scenario 1} & 2010 & 1 & $-2,4$ & 5 & $-1,11$ & 22 & 12, 32 & 22 & 15, 29 & 16 & 8, 24 \\
\hline & 2020 & 5 & $-4,14$ & 72 & 52,92 & 188 & 155,221 & 248 & 225,271 & 177 & 149,205 \\
\hline & 2030 & 18 & 5,31 & 163 & 135,191 & 326 & 280,372 & 546 & 512,580 & 358 & 319,397 \\
\hline & 2040 & 30 & 14,46 & 321 & 285,357 & 473 & 416,530 & 862 & 820,904 & 556 & 507,605 \\
\hline & 2050 & 39 & 20,58 & 552 & 508,596 & 621 & 555,682 & 1210 & 1159,1261 & 753 & 695,811 \\
\hline \multirow[t]{5}{*}{ Scenario 2} & 2010 & 2 & $-1,5$ & 24 & 18,30 & 54 & 44,64 & 82 & 72, 90 & 59 & 51,57 \\
\hline & 2020 & 25 & 16,34 & 283 & 264,302 & 589 & 556,622 & 850 & 828,872 & 584 & 557,611 \\
\hline & 2030 & 57 & 45,69 & 622 & 594,650 & 1008 & 962,1054 & 1611 & 1579,1643 & 1091 & 1053,1129 \\
\hline & 2040 & 75 & 59,91 & 1060 & 1025,1095 & 1532 & 1476,1588 & 2436 & 2395,2477 & 1627 & 1579,1675 \\
\hline & 2050 & 114 & 95,133 & 1601 & 1558,1644 & 2075 & 2009,2141 & 3423 & 3374,3472 & 2220 & 2163,2277 \\
\hline
\end{tabular}

Scenario $1,1 \%$ reduction in BMI across the population; Scenario $2,5 \%$ reduction in BMI across the population.

395878 cases in 2030 and by 877311 cases in 2050 . With a $5 \%$ reduction in BMI, more cumulative cases are avoided. Cancer cases are decreased by 41328 in 2030 and by 82655 in 2050. In 2030 and 2050, respectively 450981 and 1160805 cumulative cases of CHD and stroke are avoided. Diabetes is reduced by 1168056 cases in 2030 and by 2481845 cases in 2050 .
The economic burden of the BMI-related diseases across each of the three scenarios is presented in Table 5. The cancer costs double when projected until 2050. The CHD and stroke costs increase from \$US 324 million to \$US 557 million and \$US 797 million in 2030 and 2050 respectively. All diseases, calculated to cost \$US 806 million in 2010 , could increase to $\$$ US $1 \cdot 2$ billion in 2030 and to 
Table 5 Projected health-care costs (in millions of \$US) of various obesity-related diseases in year 2010 to 2050 among Mexican adults according to different scenarios

\begin{tabular}{|c|c|c|c|c|c|c|c|c|c|}
\hline \multirow[b]{2}{*}{ Year } & \multicolumn{3}{|c|}{ Scenario 0} & \multicolumn{3}{|c|}{ Scenario 1} & \multicolumn{3}{|c|}{ Scenario 2} \\
\hline & $\begin{array}{c}\text { Eight } \\
\text { cancers }\end{array}$ & $\begin{array}{l}\mathrm{CHD} \text { and } \\
\text { stroke }\end{array}$ & $\begin{array}{l}\text { All thirteen } \\
\text { diseases }\end{array}$ & $\begin{array}{c}\text { Eight } \\
\text { cancers }\end{array}$ & $\begin{array}{l}\mathrm{CHD} \text { and } \\
\text { stroke }\end{array}$ & $\begin{array}{l}\text { All thirteen } \\
\text { diseases }\end{array}$ & $\begin{array}{c}\text { Eight } \\
\text { cancers }\end{array}$ & $\begin{array}{l}\mathrm{CHD} \text { and } \\
\text { stroke }\end{array}$ & $\begin{array}{l}\text { All thirteen } \\
\text { diseases }\end{array}$ \\
\hline 2010 & 50 & 324 & 806 & 50 & 317 & 796 & 49 & 310 & 783 \\
\hline 2011 & 53 & 346 & 837 & 52 & 336 & 823 & 51 & 326 & 804 \\
\hline 2012 & 54 & 362 & 862 & 54 & 351 & 846 & 53 & 339 & 823 \\
\hline 2013 & 56 & 370 & 880 & 56 & 362 & 867 & 55 & 348 & 838 \\
\hline 2014 & 57 & 384 & 902 & 58 & 372 & 886 & 56 & 359 & 855 \\
\hline 2015 & 58 & 395 & 923 & 59 & 381 & 903 & 58 & 368 & 870 \\
\hline 2016 & 60 & 404 & 942 & 60 & 392 & 922 & 60 & 376 & 885 \\
\hline 2017 & 62 & 416 & 964 & 62 & 402 & 941 & 61 & 385 & 901 \\
\hline 2018 & 64 & 425 & 984 & 63 & 408 & 957 & 62 & 392 & 914 \\
\hline 2019 & 65 & 435 & 1004 & 65 & 420 & 978 & 63 & 401 & 930 \\
\hline 2020 & 67 & 445 & 1025 & 67 & 429 & 997 & 64 & 407 & 943 \\
\hline 2021 & 69 & 456 & 1047 & 68 & 438 & 1016 & 65 & 414 & 959 \\
\hline 2022 & 70 & 463 & 1066 & 70 & 447 & 1035 & 66 & 422 & 976 \\
\hline 2023 & 72 & 474 & 1089 & 71 & 457 & 1055 & 68 & 432 & 995 \\
\hline 2024 & 73 & 486 & 1112 & 73 & 470 & 1080 & 70 & 443 & 1015 \\
\hline 2025 & 74 & 496 & 1133 & 74 & 481 & 1101 & 72 & 452 & 1034 \\
\hline 2026 & 77 & 508 & 1158 & 75 & 492 & 1122 & 73 & 462 & 1053 \\
\hline 2027 & 78 & 519 & 1181 & 77 & 502 & 1143 & 75 & 471 & 1073 \\
\hline 2028 & 79 & 532 & 1205 & 78 & 512 & 1164 & 76 & 482 & 1093 \\
\hline 2029 & 80 & 544 & 1228 & 79 & 523 & 1186 & 78 & 493 & 1114 \\
\hline 2030 & 81 & 557 & 1254 & 81 & 537 & 1211 & 78 & 506 & 1137 \\
\hline 2031 & 82 & 569 & 1277 & 82 & 547 & 1231 & 80 & 516 & 1157 \\
\hline 2032 & 84 & 580 & 1300 & 83 & 557 & 1252 & 82 & 526 & 1177 \\
\hline 2033 & 85 & 592 & 1324 & 84 & 567 & 1272 & 84 & 537 & 1199 \\
\hline 2034 & 87 & 604 & 1348 & 85 & 580 & 1296 & 85 & 548 & 1220 \\
\hline 2035 & 87 & 618 & 1372 & 86 & 590 & 1317 & 86 & 559 & 1240 \\
\hline 2036 & 88 & 632 & 1397 & 87 & 604 & 1340 & 87 & 570 & 1260 \\
\hline 2037 & 89 & 642 & 1419 & 88 & 616 & 1363 & 87 & 583 & 1281 \\
\hline 2038 & 90 & 654 & 1441 & 90 & 628 & 1385 & 90 & 596 & 1305 \\
\hline 2039 & 91 & 671 & 1469 & 91 & 641 & 1408 & 91 & 607 & 1325 \\
\hline 2040 & 92 & 684 & 1492 & 92 & 650 & 1427 & 92 & 617 & 1345 \\
\hline 2041 & 94 & 697 & 1517 & 94 & 660 & 1448 & 93 & 628 & 1365 \\
\hline 2042 & 96 & 708 & 1540 & 96 & 669 & 1467 & 95 & 637 & 1382 \\
\hline 2043 & 97 & 718 & 1559 & 97 & 681 & 1490 & 95 & 646 & 1400 \\
\hline 2044 & 97 & 726 & 1576 & 98 & 689 & 1507 & 96 & 656 & 1417 \\
\hline 2045 & 98 & 738 & 1598 & 99 & 701 & 1528 & 97 & 666 & 1435 \\
\hline 2046 & 99 & 752 & 1623 & 101 & 711 & 1548 & 98 & 675 & 1452 \\
\hline 2047 & 101 & 763 & 1644 & 102 & 720 & 1567 & 99 & 682 & 1466 \\
\hline 2048 & 102 & 773 & 1663 & 103 & 731 & 1588 & 100 & 694 & 1486 \\
\hline 2049 & 103 & 785 & 1683 & 103 & 739 & 1603 & 100 & 703 & 1501 \\
\hline 2050 & 104 & 797 & 1706 & 104 & 748 & 1621 & 102 & 709 & 1514 \\
\hline Total & 3263 & 23042 & 51548 & 3257 & 22057 & 49687 & 3194 & 20941 & 46917 \\
\hline
\end{tabular}

Scenario 0, no BMI reduction; Scenario 1, 1\% reduction in BMI across the population; Scenario 2, 5 \% reduction in BMI across the population.

\$US 1.7 billion in 2050. Table 5 also shows that a $1 \%$ reduction in BMI prevalence could save a total of \$US 43 million in 2030 and \$US 85 million in 2050 . A 5\% BMI decrease saves \$US 117 million in 2030 and \$US 192 million in 2050.

\section{Discussion}

Our analysis shows that the prevalence of overweight and obesity and the associated disease and economic burden will increase substantially in Mexico. By 2050, the prevalence of normal weight individuals will decrease to $12 \%$ from $32 \%$ in males and to $9 \%$ from $26 \%$ in females, and more people will be obese than overweight. About 12 million diabetes cases and 8 million heart disease cases are projected in 2050 alone. For the thirteen diseases considered, costs of \$US 806 million are estimated for 2010 and projected to increase to $\$$ US $1 \cdot 2$ billion and \$US 1.7 billion in 2030 and 2050 respectively.

We also found that a $1 \%$ reduction in mean BMI could save a total of \$US 43 million in 2030 and \$US 85 million in 2050. A 5\% decrease saves \$US 117 million in 2030 and \$US 192 million in 2050. This shows considerable avoidable health-care costs and future burdens of disease. By translating these costs to per capita terms, these estimates provide measures that can be used in developing cost-effectiveness analysis of interventions to reduce obesity.

Mexico's public health community and policy makers must develop and implement effective public health interventions to halt the increasing trend in obesity 
prevalence. All programmes and policies need to be evaluated in order to refine and adapt effective actions that might contribute to controlling the epidemic. A very carefully designed public health strategy involving all social sectors, and with important participation of the state regulating and protecting the population and creating incentives for healthier lifestyles at the family, community, school, work and country levels, is necessary. Our analysis demonstrates that a small reduction in BMI at the national level over the years could tackle the disease burden, generating important savings and benefits for the country. Thus higher priority and investment in developing comprehensive, multisectoral programmes with an evaluation component and process indicators are urgently needed.

In Mexico, as in many other countries, the majority of the health budget is going into treatment $(73.5 \%)$ rather than prevention and public health (2.7\%). In 2006, Mexican total health-care cost for diabetes, CVD and obesity was approximately 40 billion Mexican pesos, which represents $7 \%$ of the total health-care budget. Only $4 \cdot 2 \%$ of the total health-care budget is destined for obesity and $55 \cdot 2 \%$ for $\mathrm{CVD}^{(22)}$. It is important to reallocate the budget appropriately and invest in obesity prevention.

As part of the proposed solution to tackle the problem, we projected possible outcomes of two interventions with an impact on mean BMI of the population. We found that a $1 \%$ reduction in mean BMI could save a total of \$US 43 million in 2030 and \$US 85 million in 2050. A 5\% decrease saves \$US 117 million in 2030 and \$US 192 million in 2050. This shows considerable avoidable health-care costs and future burdens of disease. Although it is possible that this reduction can be reached by national prevention programmes at an expense of approximately \$US 12 per capita ${ }^{(23)}$, it is likely that an additional fund needs to be considered in order to prevent obesity-related diseases and no actual saving can be made at the initial stage. Still, the priority should remain the health of the population and not saving money.

Since 2007, the Mexican Federal Administration has developed several actions to tackle obesity, for example: (i) 'Unidades de Especialidades Médicas' (UNEMES) in 2007, a primary health clinic system focused on treatment of NCD; (ii) the national agreement for healthy eating, 'Acuerdo Nacional para la Salud Alimentaria. Estrategia contra el Sobrepeso y la Obesidad', in 2010; (iii) the guidelines for food and beverage sales in schools, 'Lineamientos para el Expendio o Distribución de Alimentos o Bebidas', in 2010; and (iv) 'Five Steps for Your Health' ('Cinco pasos por tu salud') in 2010. These all aim to promote healthy eating, lifestyle and early detection of obesity's health consequences. Nevertheless, evaluating the cost-effectiveness of these projects will take longer than planned.

While the projections presented here are based on the best data available, the study has some limitations. First, some of the data parameters were unavailable for Mexico and were interpolated using information from other countries; therefore the results could be under- or overestimated. For six cancers we used the survival rates from the USA. Mexican health-care resources are substantially scarce compared with the USA; the USA has the highest health-care expenditure per capita in the world focusing on early screening, whereas Mexican health care places a greater focus on hospital care, resulting in lower survival rates than in the $\mathrm{USA}^{(24,25)}$. Therefore, in using survival from the USA we may have overestimated cancer survival for Mexico, and possibly underestimated the burden of disease. Despite this, the projected cancer incidence carries a substantial health and economic burden that may be even higher in the actual population and should be a high priority on the health-care agenda. Moreover, there is evidence of different evolutions and patterns of natural history in nutrition-related chronic diseases. Diabetes mellitus prevalence is higher in Mexicans in contrast to European and American populations ${ }^{(26)}$. Half of the Mexican population with the condition have not been checked, and the ones diagnosed have poor control. The same holds with hypertension, so complications from these diseases are higher than in developed countries ${ }^{(27)}$. This may underestimate disease prevalence and health-care costs. These aspects have not been considered for the projections.

Second, height is increasing in Mexico due to successful national prevention policies against child undernutrition (e.g. micronutrient programmes for children) ${ }^{(5,28)}$. This will have a protective effect against obesity which has not been accounted for in the simulation model. However, the expected improvement in height in the next few years probably will be small. Third, a population with higher energy intake also has a higher intake of most nutrients, including $\mathrm{Na}$. A reduction in BMI as a result of healthier diets will also cause reductions in $\mathrm{Na}$ intake, thus additional benefits could be expected from intensive policy to promote healthier diets. Fourth, many other effects of obesity were not considered in the analysis. The savings in expenditure due to complications of obesity could be much higher. Finally, aggressive communication campaigns against obesity, a national agreement for healthy nutrition, guidelines for foods at schools and other successful initiatives have been launched recently by the Mexican Government and might contribute to partial reductions in future prevalence ${ }^{(29)}$. At present, however, these programmes have not been evaluated and it is difficult to argue about their effectiveness.

\section{Conclusion}

Obesity rates across Mexico are alarming. The present study serves to highlight the need for better-quality surveillance data and effective public health interventions to curb rising obesity rates. Without these, the costs of obesity will place a huge financial burden on the public health system. 


\section{Acknowledgements}

Sources of funding: GlaxoSmithKline provided a nondiscretionary educational grant to support this project (grant number 27875780). Conflicts of interest: The authors declare to have no conflicts of interest. Ethics: Ethical approval was not required. Author contributions: K.R. identified data inputs, conducted the analysis and drafted the manuscript. M.B. constructed the model and did all the simulations. T.M., S.B., L.M.S.R., D.L., G.M., L.W., F.K. and K.M. provided critical guidance and edits. All authors reviewed, approved and edited the manuscript.

\section{References}

1. Barquera S, Campos-Nonato I, Hearnandes-Barrera L et al (2006) Obesity and central adiposity in Mexican adults: results from the Mexican National Health and Nutrition Survey 2006. Salud Publica Mex 51, Suppl. 4, S595-S603.

2. Sánchez-Castillo $\mathrm{CP}$, Velásquez-Monroy $\mathrm{O}$, Lara-Esqueda A et al. (2005) Diabetes and hypertension increases in a society with abdominal obesity: results of the Mexican National Health Survey 2000. Public Health Nutr 8, 53-60.

3. Secretaria de Salud (2008) Principales causes de mortalidad general, 2008. Nacional. http://www.sinais.salud.gob.mx/ descargas/xls/m_005.xls (accessed January 2012).

4. Stevens G, Dias RH, Thomas KJA et al. (2008) Characterizing the epidemiological transition in Mexico: national and subnational burden of diseases, injuries, and risk factors. PLoS Med 5, e125.

5. Organisation for Economic Co-operation and Development (2010) Obesity and The Economics of Prevention: Fit not Fat - Mexico Key Facts. http://www.oecd.org/document/32/ 0,3746,en_2649_33929_46038752_1_1_1_1,00.html（accessed June 2012).

6. Secretaría de Salud (2010) Acuerdo Nacional para la Salud Alimentaria: estrategia contra el sobrepeso y la obesidad, pp. 12-13. Mexico DF: Sub-Secretaría de Prevención y Promoción de la Salud de la Secretaría de Salud.

7. Wang YC, McPherson K, Marsh T et al. (2011) Health and economic burden of the projected obesity trends in the USA and the UK. Lancet 378, 815-825.

8. Olaiz G, Rojas R, Barquera S et al. (2003) Encuesta Nacional de Salud 2000. tomo 2: La salud de los adultos. Cuernavaca, Morelos: Instituto Nacional de Salud Pública.

9. Olaiz G, Rivera J, Shamah T et al. (2006) Encuesta Nacional de Salud y Nutrición 2006. Cuernavaca, Morelos: Instituto Nacional de Salud Pública.

10. Arroyo P, Loria A, Fernandez V et al. (2000) Prevalence of pre-obesity and obesity in urban adult Mexicans in comparison with other large surveys. Obes Res 8, 179-185.

11. Rivera J, Shamah T, Villalpando S et al. (2001) Encuesta Nacional de Nutrición 1999. Estado nutricio de niños y mujeres en México. Cuernavaca, Morelos: Instituto Nacional de Salud Pública.

12. Lobstein T \& Leach RJ (2010) Workpackage 7: Overweight and Obesity. Report on data collection for overweight and obesity prevalence and related relative risks. Data documentation for the Dynamic Modelling for Health Impact Assessment (DYNAMO-HIA) Project. http://www.dynamo-hia. eu/object_binary/O3055_BMI_WP7-datareport_20100317.pdf
13. World Health Organization (2008) Health statistics and health information systems. Disease and injury country estimates. Burden of disease. http://www.who.int/health info/global_burden_disease/estimates_country/en/index.html (accessed July 2011)

14. International Agency for Research on Cancer, World Health Organization (2008) The GLOBOCAN Project 2008. http:// globocan.iarc.fr/ (accessed July 2011).

15. Instituto Mexicano del Seguro Social (2008) Grupos Relacionados con el Diagnóstico; Costo Medico Tecnico. http://www.imss.gob.mx/profesionales/Documents/GRD_ IMSS.pdf (accessed January 2012).

16. Barcelo A, Aedo C, Rajpathak S et al. (2003) The cost of diabetes in Latin America and the Caribbean. Bull World Health Organ 81, 19-27.

17. Butland B, Jebb S, Kopelman P et al. (2007) Foresight Tackling Obesities: Future Choices - Project Report. London: Government Office for Science.

18. Kopelman P, Jebb SA \& Butland B (2007) Executive summary: Foresight: 'Tackling Obesities: Future Choices' project. Obes Rev 8, Suppl. 1, vi-ix.

19. McPherson K, Marsh T \& Brown M (2007) Foresight. Tackling Obesities: Future Choices - Modelling Future Trends in Obesity \& Their Impact on Health. London: Government Office for Science.

20. United Nations, Department of Economic and Social Affairs, Population Division, Population Estimates and Projections Section (2010) World Population Prospects, the 2010 Revision. http://esa.un.org/unpd/wpp/index.htm (accessed July 2011).

21. Fishman GS (1995) Monte Carlo: Concepts, Algorithms, and Applications. New York: Springer.

22. Neufeld LM (2007) Lecciones aprendidas en la evaluación del Programa Oportunidades. Salud Publica Mex 49, número especial, E242-E244; available at http://redalyc. uaemex.mx/pdf/106/10649091.pdf

23. Secretaría de Salud (2010) Acuerdo Nacional para la Salud Alimentaria: estrategia contra el sobrepeso y la obesidad. Mexico DF: Sub-Secretaría de Prevención y Promoción de la Salud de la Secretaría de Salud.

24. World Health Organization (2000) The World Health Report 2000. Health Systems: Improving Performance. Geneva: WHO; available at http://www.who.int/whr/2000/ en/whrO0_en.pdf

25. World Health Organization (2009) Health Expenditure: Health Expenditure per capita. http://www.who.int/whosis/ whostat/EN_WHS09_Table7.pdf (accessed December 2012).

26. Centers for Disease Contol and Prevention (2004) National diabetes fact sheet, United States, 2003. Atlanta, GA: CDC.

27. Ávila Burgos L, Cahuana Hurtado L \& González Domínguez D (editors) (2006) Cuentas en diabetes mellitus, enfermedades cardio. Fes y obesidad: México 2006, 1st ed. Cuernavaca, Morelos: Instituto Nacional de Salud Pública, Centro de Investigación en Sistemas de Salud.

28. World Health Organization (2011) Global Health Observatory. Prevalence of raised blood pressure, ages 25+, age standardized: Both sexes, 2008. Geneva: WHO; available at http://gamapserver.who.int/mapLibrary/Files/Maps/Global_ BloodPressurePrevalence_BothSexes_2008.png

29. Neufeld LM, García-Guerra A, Leroy J et al. (2006) Impacto del Programa Oportunidades en nutrición y alimentación en zonas urbanas de México. In Evaluación externa del impacto del Programa Oportunidades, pp. 29-124 [B HernándezPrado and M Hernández-Ávila, editors]. Cuernavaca, Morelos: Instituto Nacional de Salud Pública. 